\title{
Evaluation of radiographic magnification in lateral cephalograms obtained with different X-ray devices: Experimental study in human dry skull
}

José Rino Neto¹, João Batista de Paiva², Gilberto Vilanova Queiroz³, Miguel Ferragut Attizzani, Hiroshi Miasiro Junior ${ }^{4}$

Objective: The purpose of this study was to evaluate the influence of the magnification factor of the radiographic image in angular, linear and proportional measurements. Methods: From a dried human skull where metallic spheres with predetermined size were fixed $(1.0 \mathrm{~mm}), 14$ radiographs were obtained in devices of three different manufacturers: Panoura, Instrumentarium and Tomeceph. The Pearson correlation test was used to investigate the relationship between the rate of radiographic magnification and the cephalometric measurements assessed. Results: According to the results, the linear measurements showed a high positive correlation, pointing out great influence of the magnification factor, while the angular and proportional measurements did not correlate. Conclusions: Comparisons between linear cephalometric measurements obtained with different devices from the same manufacturer showed maximum rates of expansion of $0.6 \%, 1.25 \%$ and $2.3 \%$, respectively, for the devices from Instrumentarium (OP-100, Instrumentarium, Finland), Panoura (10CSU, Yoshida, Japan) and Satelec/Tomeceph (XMind, Satelec/Tomeceph Orion Corporation, Finland).

Keywords: Orthodontics. Diagnostic. Radiograph. Radiographic magnification.

Objetivo: avaliar a influência do fator de magnificação da imagem radiográfica nas grandezas angulares, lineares e proporcionais. Métodos: a partir de um crânio seco humano, no qual foram fixadas esferas metálicas de dimensões pré-definidas (1,0mm de diâmetro), 14 telerradiografias foram obtidas em diferentes aparelhos de três fabricantes: Panoura, Instrumentarium e Tomeceph. Foi realizada a análise estatística descritiva e utilizado o teste de correlação de Pearson para verificar a relação entre a taxa de magnificação radiográfica e as grandezas cefalométricas analisadas. Resultados: as medidas lineares apresentaram alta correlação positiva, evidenciando grande influência do fator de magnificação sobre essas grandezas, ao passo que as angulares e proporcionais não apresentaram correlação. Conclusão: comparações entre medidas cefalométricas lineares obtidas com diferentes aparelhos do mesmo fabricante demonstraram taxas de ampliações máximas de 0,6\%, 1,25\% e 2,3\%, respectivamente, para os aparelhos Instrumentium (OP-100 Instrumentarium), Panoura (10CSU Yoshida) e Satelec/Tomeceph (XMind Satelec/Tomeceph Orion Corp).

Palavras-chave: Ortodontia. Diagnóstico. Radiografia. Ampliação radiográfica.

${ }^{1}$ Associate Professor, Department of Orthodontics, FOUSP

${ }^{2}$ Head Professor, Department of Orthodontics, FOUSP

${ }^{3} \mathrm{PhD}$ in Orthodontics. FOUSP. Professor of the Specialization Course in Orthodontics, ABENO.

${ }^{4} \mathrm{MSc}$ in Orthodontics, FOUSP. Specialist in Orthodontics, Department of Orthodontics, FOUSP FUNDECTO / FOUSP.

» The authors report no commercial, proprietary or financial interest in the products or companies described in this article.
How to cite this article: Rino Neto J, Paiva JB, Queiroz GV, Attizzani MF, Miasiro Junior H. Evaluation of radiographic magnification in lateral cephalograms obtained with different X-ray devices: Experimental study in human dry skull. Dental Press J Orthod. 2013 Mar-Apr;18(2):17.e1-7.

Submitted: October 13, 2008 - Revised and accepted: March 09, 2009

Contact address: José Rino Neto

Av. Professor Lineu Prestes, 2227 - Cidade Universitária - Brazil

CEP: 05.508-000 - São Paulo/SP - E-mail: jrneto@usp.br 


\section{INTRODUCTION}

Lateral cephalometric radiographs are important in growth analysis, diagnosis, treatment planning and results. The basic equipment to obtain them consists of an X-ray source, an adjustable cephalostat, a chassis for the $\mathrm{X}$-ray film with intensifying screens and the support to the chassis. All these components are rigidly attached to each other and arranged at predetermined distances, thus creating a unit.

For obtaining reliable images, one must know, determine, and if possible, control the several variables related to its performing. Freitas et a ${ }^{11}$ pointed didactically the many factors related to the formation of radiographic image. One relates to the geometry and it is also related to the principles of formation of radiographic images, being directly related to the position of the emitting source of X-rays, the object and the film, that are governed by the principle of geometric optics.

Regarding the use of cephalometric radiographs, either lateral or frontal, the factors that have great influence on the image are: The radiographic distortion, radiographic magnification and errors in the delimitation of the points and in the cephalometric measurements. ${ }^{1-8,11,12,16-19,23}$

\section{Radiographic distortion}

In obtaining lateral cephalometric radiographs, the cephalostat allows the midsagittal plane of the individual to remain parallel to the radiographic film and perpendicular to the X-ray beams. Horizontal head rotations cause changes in the alignment between beams and the object, causing distortions in the image, consisting of the mistaken duplication of a particular structure or area, causing inaccuracies in the analysis of overlaps that could be performed. ${ }^{22}$

\section{Radiographic magnification}

Because the X-rays emanating from the source have a divergent pattern, there is a variation in the amount of magnification of the object in any radiograph. ${ }^{2,22}$ To reduce the magnification in lateral cephalometric radiographs, one should increase the distance between the source of X-rays and the object to be radiographed in order to take advantage of the central beam, which is flatter, and also decrease the distance between the object and the radiographic film. ${ }^{4,9,15,21}$ It is recommended a distance of $152.4 \mathrm{~cm}$ between the X-ray source and the sagittal plane, considering that increasing the distance would result in loss of penetration of rays. ${ }^{6}$ According to Weens ${ }^{27}$ magnification of craniofacial structures varies from almost $0 \%$ up to $24 \%$ in objects close to the film or objects in the exact center of the rays. This magnification is not constant for all possible sagittal plane of patient. Structures located closer to the film will present lower magnification comparing to those closer to the rays. As mentioned earlier, another variable, considering the magnification factor, would be the distance between the midsagittal plane of the individual and the film. To minimize variations between different patients and obtain consistent measurements in an individual over time, it is recommended to maintain constant this distance. An average distance of $15 \mathrm{~cm}$ is often used, although it would be ideal to position the frame as close to the patient's head as possible to reduce the magnification (Fig 1).

\section{Errors in tracing landmarks and cephalometric measurements}

In a study by Bjork and Solow, ${ }^{7}$ it was observed that the tracing process introduces significant systematic errors. Depending on the anatomical structures assessed, there is more or less variability in the tracing of landmarks. ${ }^{5}$

The reproducibility in the tracing of landmarks and linear measurements was studied by Midtgard et al. ${ }^{17} \mathrm{Ac}-$ cording to the authors, measurement errors are directly dependent on the precise tracing of the landmarks. In a similar study, Savage et $\mathrm{al}^{21}$ found out that the reproducibility is dependent upon and varies according to the

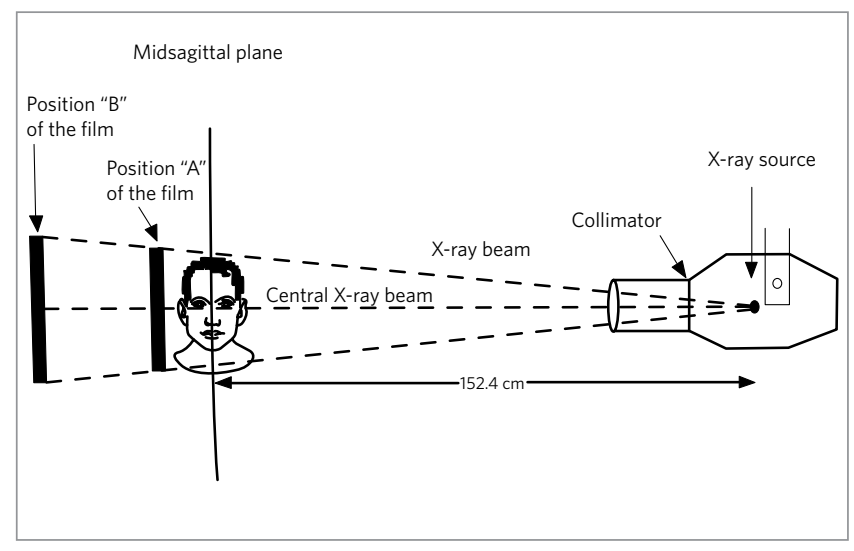

Figure 1 - Diagram showing the process of radiographic magnification. In the position " $\mathrm{A}$ " of the film due to the proximity of this one in relation to the patient, there will be less image magnification comparing to the position "B". (Source: Weems, ${ }^{27}$ 1995). 
evaluated structure, and it was not associated to the level of experience of the observer or the quality of the radiographic image for tracing.

The cephalometric radiographs are used by both clinical orthodontists and researchers, that through angular, linear and proportional measurements seek to describe the craniofacial morphology and compare the results of different orthodontic treatments. In order to increase the accuracy in the interpretation of cephalometric measurements, the objectives of this study are:

a) To verify the possible influence of radiographic magnification on angular, linear and proportional measurements, formed by anatomical points located in the midsagittal plane or by a combination of points in the midsagittal plane and lateral regions of the face.

b) To check the rates of radiographic magnification in lateral cephalometric radiographs obtained in different machines from the same manufacturer.

\section{MATERIAL AND METHODS}

The sample consisted of 14 lateral cephalometric radiographs of a dry skull belonging to the Institute of Biomedical Sciences, University of São Paulo, obtained using 14 different X-rays devices. The device models provided by radiological institutes were Panoura (10CSU-Yoshida, Japan), Instrumentarium (OP100, Instrumentarium, Finland) and Satelec/Tomeceph (XMindSatelec / Tomeceph-Orion Corp., Finland).

The position of the skull was oriented in the cephalostat, with the Frankfort horizontal plane parallel to the horizon, while maintaining the midsagittal plane perpendicular to it. The ear rods were inserted into the external auditory canal, preventing rotation of the skull and then adjusted to nasal positioner for maintenance of the position (Fig 2). To standardize the acquisition of the radiographs, only devices whose chassis were positioned on the right side of the skull were used. The upper teeth were fixed to the lower ones with acrylic resin to maintain constant the relation between the mandible and the skull, avoiding errors in the measurements. Due to the difference between the specifications of the devices, their adjustment was based on the quality of the radiographic image produced, especially in the sharpness of radiopaque markers. The brand of films used were Kodak, 18x24 T-MAT G/RA. The radiographic processing was performed in the radiology institutes themselves, always using automatic processors.
In order to eliminate errors in the identification of landmarks that could lead to errors of reproducibility and measurement, ${ }^{5,7,12,14,16,17,19}$ radiopaque markers were fixed in dry skull (standardized steel balls with $1.0-\mathrm{mm}$ diameter) at the sites described in Table 1 and shown in Figures 3, 4 and 5. In relation to points located outside the midsagittal plane, it was advocated fixing the metallic markers on the right side of the skull to make them closer to the chassis and to have the smallest magnification. ${ }^{22}$

After obtaining the lateral cephalometric radiographs, they were scanned. The landmarks were traced on the metal spheres, using the Radiocef program (RadioMemory-Brazil). The lines and plans shown on Figure 6 and Table 2 were outlined for evaluation.

Further, we evaluated the cephalometric measurements described on Tables 3, 4, 5.

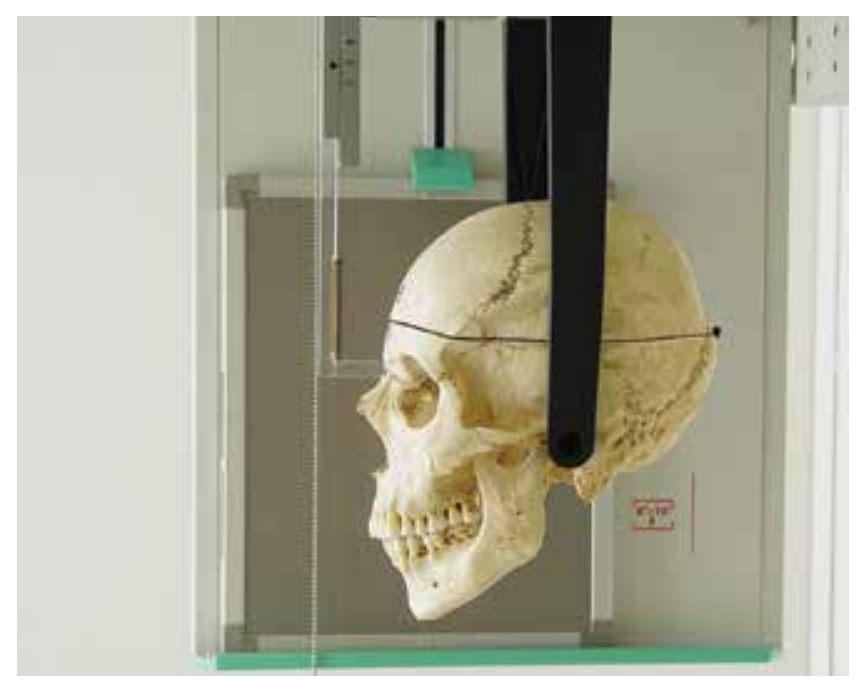

Figure 2 - Positioning the skull on the cephalostat.

\begin{tabular}{ll} 
Table 1 - Anatomical structures. \\
\hline Nasion (N) & $\begin{array}{l}\text { Anterior-most point of frontonasal suture } \\
\text { The deepest portion of the anterior concavity of } \\
\text { the sella turcica. }\end{array}$ \\
\hline Anterior sella (AS) & $\begin{array}{l}\text { Vertex of the anterior nasal spine. } \\
\text { Anterior nasal spine (ANS) }\end{array}$ \\
\hline Posterior nasal spine (PNS) & $\begin{array}{l}\text { Vertex of the posterior nasal spine. } \\
\text { Point A }\end{array}$ \\
\hline Menton (Me) & $\begin{array}{l}\text { The deepest point of the anterior concavity in } \\
\text { the malla. }\end{array}$ \\
Gonion (Go) & $\begin{array}{l}\text { Most posterior inferior point on the mandibular } \\
\text { angle. }\end{array}$ \\
\hline Xi & $\begin{array}{l}\text { The geometric center of the ramus of the } \\
\text { mandible }\end{array}$ \\
\hline
\end{tabular}




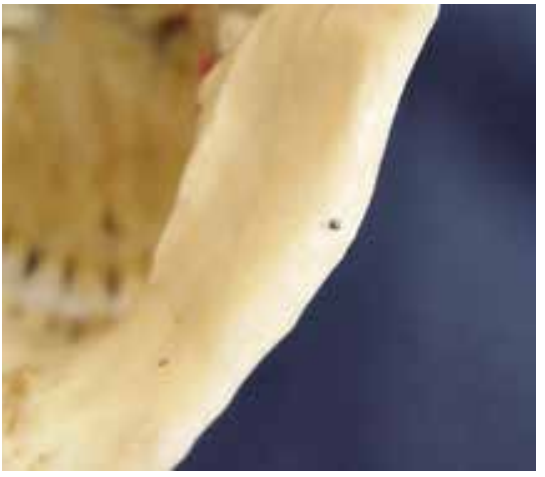

Figure 3 - View of the radiopaque marker located in the mandibular angle.

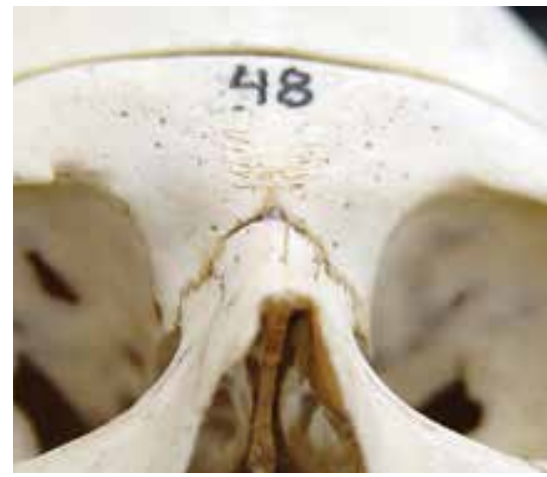

Figure 4 - View of the radiopaque marker located in the frontonasal suture, corresponding to the point N.

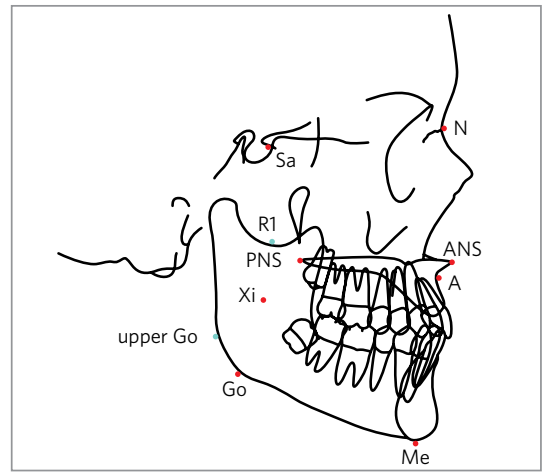

Figure 5 - Scheme of the dry skull, with the representation of the sites where the radiopaque markers were attached.
Table 2 - Lines and planes.

\begin{tabular}{ll}
\hline N-A & Line joining nasion and A point \\
Sa-N & Line joining the anterior sella and nasion \\
Go-Me & Line joining gonion and menton \\
Go-ANS & Line joining gonion and anterior nasal spine \\
ANS-PNS & Line joining anterior nasal spine and posterior nasal spine \\
Xi-ANS & Line joining point $X i$ and the anterior nasal spine \\
Xi-Me & Line joining point $X i$ and the menton \\
\hline
\end{tabular}

Table 3 - Linear measurements.

\begin{tabular}{ll}
\hline Sa-N & $\begin{array}{l}\text { Distance between Sa and N points. } \\
\text { Located in the midsagittal plane. }\end{array}$ \\
Go-Me & $\begin{array}{l}\text { Distance between the Go and Me points. Plane with one } \\
\text { structure on the right side and one on the midsagittal plane. }\end{array}$ \\
\hline
\end{tabular}

Table 4 - Angular measurements.

\begin{tabular}{ll}
\hline Sa.N.A & $\begin{array}{l}\text { Angle formed by lines Sa-N and N-A. Angle formed by } \\
\text { structures located in the midsagittal plane }\end{array}$ \\
ANS.Xi.Me & $\begin{array}{l}\text { Angle formed by lines connecting the points ANS-Xi and Xi- } \\
\text { Me. Angle formed by structures located in the midsagittal } \\
\text { plane and in the right side. }\end{array}$ \\
\hline
\end{tabular}

The measurements were obtained by a single operator, twice, at different times, and their means were considered for analysis. The angular and linear cephalometric measurements were presented as means, medians and standard deviations. To evaluate the accuracy in the positioning of the skull in the cephalostat, two new lateral cephalometric radiographs were obtained in five of the devices used. These measurements were compared

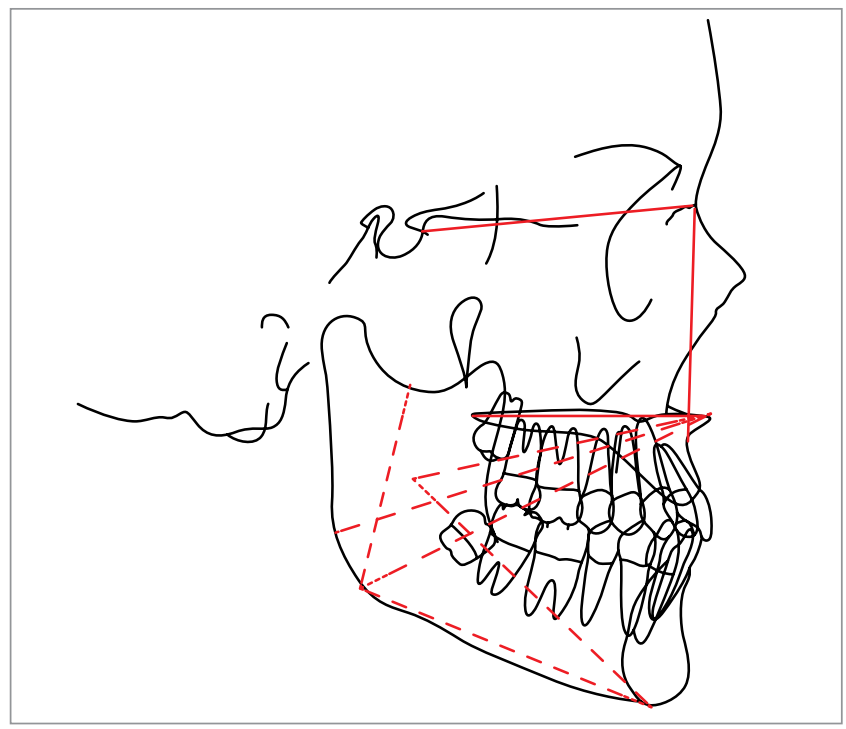

Figure 6 - Scheme of the dry skull with the cephalograms for representation of reference lines and planes.

Table 5 - Proportion measurements.

\begin{tabular}{ll}
\hline ANS-PNS:Sa-N & $\begin{array}{l}\text { Proportion between the distances ANS-PNS and As-N. } \\
\text { Formed by lines located in the midsagittal plane. }\end{array}$ \\
Sa-N:Go-Me & $\begin{array}{l}\text { Proportion between the distances Sa-N and Go-Me. } \\
\text { Formed by a line located in the midsagittal plane and one } \\
\text { on the side of the midsagittal plane }\end{array}$ \\
\hline
\end{tabular}

using the Dahlberg's formula. To evaluate the error of measurement as to the tracing of the landmarks, five lateral radiographs were randomly selected and submitted again to the digitization process.

The statistical descriptive analysis was performed and the Pearson correlation test was used to verify the relationship between the rate of radiographic magnification and the accuracy of cephalometric measurements. 


\section{RESULTS}

There were no significant differences in the evaluation of the method error according to data obtained with the Dahlberg's formula. Considering the positioning of the skull and the tracing of landmarks, the method error was $0.27 \mathrm{~mm}$ for linear measurements, $0.27^{\circ}$ for angular measurements, and $0.0 \%$ for proportion measurements. The general values obtained for cephalometric measurements are shown in Table 6. The radiographs were ordered in increasing order of magnification from the smallest value found to $\mathrm{Sa}-\mathrm{N}$ linear measurement.

Pearson's linear correlation test to investigate the correlation between the rate of magnification of radiographic images and the accuracy of cephalometric measurements showed high positive correlation for linear measurements, while the angular and proportional did not correlate (Table 7). The radiographs obtained with each brand of equipment were ordered in increasing order of magnification from the lowest value found to Sa-N linear measurement. The highest differences were of $0.6 \mathrm{~mm}, 0.8 \mathrm{~mm}$ and $1.5 \mathrm{~mm}$, respectively for the brands Instrumentarium, Panoura and Satelec.

In Table 8 one can observe the percentage values of corresponding magnifications.

\section{DISCUSSION}

The reliability of the results of this study depends on the control of errors related to the positioning of the skull in the tracing of landmarks.

Table 6 - Results of linear, angular and proportional measurements obtained with different devices.

\begin{tabular}{|c|c|c|c|c|c|c|c|}
\hline Brand & $\%$ magnif. & Sa-N & Go-Me & Sa.N.A & ANS.Xi.Me & ANS-PNS:Sa-N & Sa-N:Go-Me \\
\hline Panoura & 1 & 63.58 & 72.09 & 81.64 & 113.82 & 0.91 & 0.88 \\
\hline Panoura & 0.5 & 63.89 & 72 & 81.02 & 113.59 & 0.9 & 0.89 \\
\hline Panoura & 0.77 & 64.07 & 72.49 & 81.51 & 114.04 & 0.9 & 0.88 \\
\hline Panoura & 1.24 & 64.37 & 72.09 & 81.44 & 113.36 & 0.89 & 0.89 \\
\hline Satelec & 2.4 & 65.1 & 74.03 & 81.79 & 112.88 & 0.9 & 0.88 \\
\hline Satelec & 3.66 & 65.91 & 74.42 & 81.49 & 113.54 & 0.9 & 0.89 \\
\hline Satelec & 3.88 & 66.05 & 73.66 & 80.62 & 110.66 & 0.9 & 0.9 \\
\hline Instrumentarium & 3.95 & 66.09 & 74.29 & 81.31 & 113.95 & 0.89 & 0.89 \\
\hline Instrumentarium & 4.13 & 66.21 & 75.05 & 81.71 & 113.4 & 0.91 & 0.88 \\
\hline Instrumentarium & 4.3 & 66.3 & 74.25 & 81.84 & 114.18 & 0.89 & 0.89 \\
\hline Satelec & 4.46 & 66.42 & 74.24 & 81.6 & 114.03 & 0.9 & 0.89 \\
\hline Instrumentarium & 4.46 & 66.42 & 74.58 & 81.32 & 113.63 & 0.9 & 0.89 \\
\hline Instrumentarium & 4.57 & 66.49 & 74.78 & 81.31 & 114.29 & 0.9 & 0.89 \\
\hline Satelec & 4.76 & 66.61 & 73.55 & 81.47 & 114.61 & 0.89 & 0.91 \\
\hline
\end{tabular}

Table 7 - Pearson correlation test to evaluate the correlation between the magnification and accuracy of measurements.

\begin{tabular}{lllllll}
\hline & Sa-N & Go-Me & Sa.N.A & ANS.Xi.Me & ANS-PNS:Sa-N & Sa-N:Go-Me \\
$\%$ magnif. & 0.989803 & 0.880141 & 0.032727 & 0.065401 & -0.20471 \\
\hline
\end{tabular}

Table 8 - Results of linear measurements obtained with different devices of the same brand and model.

\begin{tabular}{|c|c|c|c|c|c|c|c|c|c|}
\hline & \multicolumn{3}{|c|}{ Panoura } & \multicolumn{3}{|c|}{ Satelec } & \multicolumn{3}{|c|}{ Instrumentarium } \\
\hline & $\%$ magnif. & Sa-N & Go-Me & $\%$ magnif. & Sa-N & Go-Me & $\%$ magnif. & Sa-N & Go-Me \\
\hline & 1 & 63.58 & 72.09 & 1 & 65.1 & 74.03 & 1 & 66.09 & 74.29 \\
\hline & 0.5 & 63.89 & 72 & 1.24 & 65.91 & 74.42 & 0.18 & 66.21 & 75.05 \\
\hline & 0.77 & 64.07 & 72.49 & 1.6 & 66.05 & 73.66 & 0.31 & 66.3 & 74.25 \\
\hline & 1.24 & 64.37 & 72.09 & 2 & 66.42 & 74.24 & 0.49 & 66.42 & 74.58 \\
\hline & - & - & - & 2.3 & 66.61 & 73.55 & 0.6 & 66.49 & 74.78 \\
\hline $\bar{x}$ & 0.88 & 63.9 & 72.16 & 1.62 & 66.02 & 73.98 & 0.51 & 66.3 & 74.59 \\
\hline S.D. & 0.31 & 0.33 & 0.22 & 0.53 & 0.58 & 0.37 & 0.31 & 0.16 & 0.33 \\
\hline Amplitude & 1.24 & 0.79 & 0.49 & 2.3 & 1.51 & 0.87 & 0.6 & 0.4 & 0.8 \\
\hline
\end{tabular}


As found in the literature, a frequent cause for the appearance of ghost images is related to improper positioning of the patient in the cephalostat. ${ }^{3,4,18,22,23}$ Studies about radiographic distortion using dry skulls are mentioned in the literature, evaluating the influence of head position in radiographs acquisition. According to Ahlqvist et al, ${ }^{3}$ rotations of the object up to $5^{\circ}$ resulted in a variation of less than $1 \%$ in length of the linear measurements. Rotations greater than $5^{\circ}$ may result in noticeable cephalometric errors, and as they are evident when positioning the patient, they must be corrected prior to exposure. In a study by Spolyar, ${ }^{22}$ it was observed a mean linear change of $1.7 \mathrm{~mm}$ ranging from 0.5 to $6.2 \mathrm{~mm}$, and mean angular changes of $1.59^{\circ}$, ranging from 0 to $5.23^{\circ}$. According to another study by Ahlqvist et al, ${ }^{4}$ cranial rotations of $5^{\circ}$ to $10^{\circ}$ were responsible for significant distortions in the angular measurements. Rotation of the head in the vertical direction ( $\mathrm{Z}$ axis) also cause a distortion, and Yoon et $\mathrm{al}^{28}$ noted that the angular measures showed projection errors smaller than the linear measures, and that the use of references located on the midsagittal plane for angular measurements showed less distortion.

In the present study to evaluate the existence of errors related to the positioning of the skull in cephalostat, two lateral cephalometric radiographs were taken at different times, totaling five $\mathrm{X}$-ray devices in the evaluation of the method error. There were no rotations of the skull, discarding the incorporation of significant distortions that could influence the cephalometric measurements.

Another problem for studies that use cephalometric radiographs, is the location of the landmarks. ${ }^{5,7,13,17,20,21,23}$ Its accuracy depends on the anatomical structure used, the radiographic image quality, visual acuity and experience of the operator on locating the landmarks, considering that great care must be taken so that measurement errors do not influence the study. ${ }^{5,7}$ In order to avoid the incorporation of errors in the identification of landmarks, we chose to fixate 1-mm radiopaque spheres in selected regions of the dry skull.

The first objective of this study was to evaluate the influence of image magnification rate on the angular, linear and proportional cephalometric measurements using lateral cephalometric radiographs. Measures located in the midsagittal plane and lateral regions of the face were analyzed.
According to Bergensen, ${ }^{6}$ the magnification rate in lateral cephalometric radiographs ranges from $4.6 \%$ to $7.2 \%$. The results are related to the location of landmarks outside the midsagittal plane and to the variation of distance between the film and the X-ray source. Adams ${ }^{1}$ in its cephalometric study also noted a significant variation for linear measurements, as the distance from the X-ray source was increased. In the same study, the angular measurements showed an average increase of $1^{\circ}$, with less variation for measures which references were in the midsagittal plane, and greater variation for those located in the mandible. The author concluded that the variation for these measures, especially the linear ones, increases as the distance from the central beam of X-rays is increased.

According to the results obtained with the Pearson's test, the linear measurements showed a high positive correlation with the rate of image magnification, while the angular and proportional ones, did not correlate (Table 7). These results confirm that the angular measurements are subjected to small changes. This was also observed for proportional measurements, which showed small correlation.

Linear measurements derived from landmarks located in the midsagittal plane showed dimensional changes that were similar to those from linear measurements that have reference points located in the midsagittal plane and in the lateral regions of the face (Table 6).

The magnification rate of radiographic images is an important factor because most orthodontic studies are based on cephalometric analysis and its measurements are made on cephalometric radiographs obtained with different X-ray devices. ${ }^{12,14}$ However, despite it is known that it influences the measures, the magnification rate is not mentioned in several articles. Radiographs collected for several years are an important source for retrospective studies; however, not knowing its magnification rates prevents its use in longitudinal studies. A possible alternative to validate the use of these radiographs would be to ensure equal magnification rates in devices with the same brand and model, allowing for the determination of the magnification rate in equal devices still in use.

The second objective of this study was to determine the amplitudes of radiographic magnification on lateral cephalometric radiographs obtained with different X-ray devices from the same brand and model. 
The images obtained with different X-ray devices of the same type and brand did not show uniform magnification rates, with linear variations ranging from 0.4 to $1.5 \mathrm{~mm}$, corresponding to magnification percentages of 0.6 to $2.3 \%$ (Table 8 ).

Although variations in the magnification rate of the device of the brand Instrumentarium were very low, generally it is not recommended to compare linear cephalometric measurements made with different X-ray devices, even those of the same brand and model, being necessary to use a ruler to standardize the magnification rate of radiographs.

\section{CONCLUSIONS}

The radiographic magnification showed high positive correlation with the linear measurements, being responsible for significant variations, regardless of whether the anatomical points were located in the midsagittal plane or lateral regions of the face. The angular and proportional measurements showed no significant correlation.

Performing cephalometric radiographs with different devices of the same brand and model does not ensure uniformity in the rates of radiographic magnification.
1. Adams JW. Correction of error in cephalometric roentgenograms. Angle Orthod. 1940;10(1):3-13.

2. Ahlquist J, Eliasson S, Welander U. The cephalographic projection. Part II. Principles of image distortion in cephalography. Dentomaxillofac Radiol. 1983:12(2):101-8

3. Ahlqvist J, Eliasson S, Welander U. The effect of projection errors on cephalometric length measurements. Eur J Orthod. 1986:8(3):141-8.

4. Ahlqvist J, Eliasson S, Welander $U$. The effect of projection errors on angular measurements in cephalometry. Eur J Orthod. 1988;10(4):353-61.

5. Baumrind S, Frantz RC. The reliability of head film measurements. 1Landmark identification. Am J Orthod. 1971;60(2):111-27.

6. Bergensen EO. Enlargement and distortion in cephalometric radiography: compensation tables for linear measurements. Angle Orthod. $1980: 50(3): 230-44$

7. Björk A, Solow B. Measurement on radiographs. J Dent Res. 1962:41(3):672-83

8. Buschang PH. Cephalometric reliability: A full ANOVA model for the estimation of true and error variance. Angle Orthod. 1987:57(2):168-75.

9. Dibbets JMH, Nolte K. Effect of magnification on lateral cephalometric studies. Am J Orthod Dentofacial Orthop. 2002;122(2):196-201.

10. Franklin JB. Certain factors of aberration to be considered in clinical roentgenographic cephalometry. Am J Orthod. 1952;38(5):351-68.

11. Freitas $L$. Fatores na produção da imagem radiográfica. In: Freitas A, et al. Radiologia odontológica. 2a ed. São Paulo: Artes Médicas; 1988. p. 61-70.

12. Hsiao T, Chang H, Liu K. A method of magnification correction for posteroanterior radiographic cephalometry. Angle Orthod 1997:67(2):137-42

13. Jarvinen S. A study of the factors causing differences in relative variability of linear radiographic cephalometric measurements. Am J Orthod Dentofacial Orthop. 1987;92(1):17-23.

14. Lew KKK. Superimposition of cephalometric radiographs with different machine magnifications. Br J Orthod. 1989;16(4):281-3.
15. Lundgren D, Owman-Moll P, Kurol J, Mårtensson B. Accuracy of orthodontic force and tooth movement measurements. Br J Orthod. 1996;23(3):241-8.

16. Macri $V$, Athanasiou AE. Sources of error in lateral cephalometry. In Athanasiou AE. Orthodontic cephalometry. England: Mosby-Wolfe; 1995. p. 125-40.

17. Midtgard J, Björk G, Linder-Aronson S. Reproducibility landmarks and errors of measurements of cephalometric cranial distances. Angle Orthod. 1976;44(1):56-61

18. Nawrath K. Moglichkeiten und Grenzen der rontgenologischen Kephalometrie. Habilitationsschrift der Johannes Gutenbeg-Universitat, Mains 1961.

19. Phillips C, Greer J, Vig P. Matteson S. Photocephalometry: errors of projection and landmark location. Am J Orthod. 1984;86(3):233-43.

20. Sandler PJ. Reproducibility of cephalometric measurements. $\mathrm{Br} \mathrm{J}$ Orthod. 1988:15(2):105-10

21. Savage AW, Showfety KJ, Yancey J. Repeated measures analysis of geometrically constructed and directly determined cephalometry points. Am J Orthod Dentofacial Orthop. 1987:91(4):295-9.

22. Spolyar JL. Head positioning error in cephalometric radiography - an implant study. Angle Orthod. 1987:57(1):77-88

23. Stabrum AE, Danielsen K. Precision in cephalometric landmark identification Eur J Orthod. 1982:4:185-96.

24. Thurow RC. Cephalometric methods in research and private practice. Angle Orthod. 1951:21(2):104-16.

25. Tng TTH, Chan TCK, Cooke MS. Validity of cephalometric landmarks. An experimental study on human skulls. Eur J Orthod. 1994;16(2):110-20.

26. Van Aken J. Geometrical errors in lateral skull x-ray projections. Nederlands Tidschrift voor Tandheelkunde. 1963;70:18-30

27. Weems RA. Radiographic cephalometric technique. In: Jacobson A. Radiographic cephalometry from basics to video imaging. Carol Stream: Quintessence; 1995. p. 39-52.

28. Yoon YJ, Kim KS, Hwang MS, Kim HJ, Choi EH, Kim KW. Effect of head rotation on lateral cephalometric radiographs. Angle Orthod. 2001;71(5):396-403. 